\title{
PHYSICAL AND VIRTUAL RECONSTRUCTION FOR AN INTEGRATED ARCHAEOLOGICAL MODEL: 3D PRINT AND MAQUETTE
}

\author{
L. Fregonese ${ }^{1}$, N. Giordani ${ }^{2}$, A. Adami ${ }^{1 *}$, G. Bachinsky ${ }^{1}$, L. Taffurelli ${ }^{1}$, O. Rosignoli $^{1}$, J. Helder $^{1}$ \\ ${ }^{1}$ Dept. of Architecture, Built Environment and construction engineering. Politecnico di Milano, Campus Mantova, Piazza d'Arco, \\ Mantova, (IT) (luigi.fregonese, andrea.adami, giulia.bachinsky, laura.taffurelli, olga.rosignoli, jacopo.helder)@ polimi.it \\ ${ }^{2}$ Museo Archeologico Nazionale di Mantova, Piazza Castello, Mantova
}

Commission II, WG II/8

KEY WORDS: 3d print, physical model, digitization, virtual reconstruction, musealization

\begin{abstract}
:
Museums perform various tasks such as collecting, cataloguing and preserving the cultural heritage $(\mathrm{CH})$. In addition, they have an institutional task, which is to disseminate the heritage, discovering the most efficient tools to tell how a monument to the origin could have looked. In this process of knowledge and dissemination, digital technologies play an important role. In fact, they allow building a digital archive in which virtual copies of found objects are available to scholars for more or less in-depth analysis. Digital archives of this type also allow the dissemination of scientific data, constituting, if published, databases accessible everywhere. The role of the digital archive is also to preserve the characteristics of the finds, which are often already deteriorated, without worsening the situation through their continuous manipulation or movement. Of course, the construction of digital copies must be done in the most rigorous way so as to guarantee scholars the truthfulness of the data being analysed, and building procedures as standardized as possible to allow their use even by unskilled personnel. Moreover, museums have the very complex task of communicating the heritage, which envisages two steps: reconstruction and communication. The first phase, reconstruction, is a very complex operation, especially in the archaeological field, where there are few documents and the hypotheses are based on principles of similarity. Since no direct reference is available, the reconstruction takes place through comparison with similar objects from the same period, the same area and with the same function. Communication, then, has the task of disseminating the results and the hypotheses made, with the most appropriate tools. 3D printing allows to build three-dimensional models of reality, and therefore immediately comprehensible, even of complex forms, not always achievable with the traditional tools of modelling tools. This article describes this complex process, and its application to the funerary aediculae monument at the Museo Archeologico di Mantova, on the occasion of the refurbishment of the museum and its exhibits. In this experience, the use of new technologies is being investigated in combination with more traditional methods of representation, the maquette, but not less effective.
\end{abstract}

\section{INTRODUCTION}

Museums in general, but the archaeological ones in particular, play a dual role. On the one hand, they often serve as an archive for all the archaeological finds of the territories belonging to the museum. They must even collect, catalogue and preserve the individual findings in the best way. Secondly, they have an institutional task which is to disseminate the heritage values. And this means, therefore, elaborating reconstructions, through the findings and their relocation, useful for telling how a monument might appear like at the origin.

In these respects, digital technologies can play an important role. In fact, they make it possible to build a digital archive in which virtual copies of the findings are available to scholars for analysis (Gonizzi Barsanti, Guidi, 2013). Moreover, this kind of digital archives or repository allow the dissemination of scientific data, constituting, if published, databases accessible everywhere. The role of the digital archive is also to preserve the characteristics of the finds, which are often already deteriorated, without worsening the situation through their continuous manipulation or movement. Obviously, the construction of digital copies must be done in the most rigorous way so as to guarantee to scholars the truthfulness of the data that is being analysed. It is, therefore, a matter of using technologies and tools that, in addition to how the object is perceived, are able to provide a representation as accurate and realistic as possible. This involves the search for excellent results both for the geometric aspects and for the surface/image itself of the object. From the geometric content you can obtain dimensions (length, width and height) and shape, but also detailed and very precise information such as weight (useful for the design, as you will see below). Textures applied to digital models, on the other hand, make it possible to recognize materials, used techniques, state of preservation or alterations.

The task of spreading the heritage is very complex and passes through two phases: interpretation/reconstruction and communication. The first phase is a very complex operation, especially in the archaeological field, where there are few documents and the hypotheses are based on principles of similarity (Renfrew, Bahn, 2006). As there is no direct reference available, the reconstruction takes place by comparing items with similar objects from the same period, the same area and the same function. However, this is not a completely hypothetical reconstruction, but rather the verification of a hypothesis. Through the above-described procedure (the comparison) some hypotheses are formulated, then they have to be validated through the archaeological finds that must be inserted in the reconstructive model in a correct way (Scopigno et al., 2011). The communication also has the task of disseminating the results and the assumptions made. Here again, it is necessary to find the most appropriate tools to play this role. The choice is made not only on the object to be represented, but also, and perhaps above all, according to the objective and the public to which the communication is directed. Two-dimensional and threedimensional representations, models, holograms and many other

\footnotetext{
* Corresponding author
} 
different technological products must always answer the questions, which are essential, "what do I want to tell?" and "to whom?" (Di Giuseppantonio et al., 2015; Galeazzi, 2016).

This paper describes the experience carried out at the Museo Archeologico di Mantova on the occasion of the partial refurbishment of its exhibition space, in particular with regard to the funeral monument of the Sarsinate type, illustrated below.

The experience, split up in several phases, has seen the digitization of the findings that can be connected to the funerary monuments excavated in Sarsina (Forlì-Cesena), the use of models for the verification of hypotheses conducted on the basis of comparisons with other monuments and the construction of a physical model that tells the results of research conducted.

\section{METHODS AND GOALS}

This research has turned its attention to two different phases of the process of knowledge and communication of cultural heritage, in the museum environment. Documentation and physical reproduction (through maquettes) are very effective tools that require, however, specific approaches.

\subsection{The documentation}

The goal of the documentation is to provide a valid support to the knowledge of the cultural asset or of the archaeological finding. It represents the first and most essential step of many processes: archiving, data sharing, dissemination, analysis, restoration and conservation interventions are just a few examples of all the operations that start from the good knowledge.

It becomes essential, however, to consider the documentation as a phase of a complex process, involving several professional actors, with different level of specialization in the use of new technologies and with diverse objectives. This allows, on one side, to have clear final objectives and, on the other, to set up a working method that can be replicated as much as possible over time. Knowing your target audience - the beneficiaries of the documentation in this case - means, in fact, understanding not only the specifications of the formats for using and sharing data, and the final product format (vector, raster, $2 \mathrm{D}$ or $3 \mathrm{D}$, etc.) but above all identifying the essential requirements of the documentation phase. As in the case of the architectural survey, the project of the documentation, through the comparison with the different stakeholders, serves therefore to define many aspects such as the expected metric accuracy and the need for colour. These desiderata must deal with the characteristics of the objects themselves (if it is possible to identify common ones), the logistics of the working spaces, the availability of instruments and tools.

According to all these parameters, when the goals are well defined and shared, it is advisable to identify a work pipeline. This is very helpful, especially if the number of objects to be documented is large, or if the working group is made up of several people. The result is thus homogeneous.

Technically, the workflow is determined by the method used for the 3D documentation: today the most common are laser scanning and photogrammetry. The choice of the most effective method is dictated by the type of result you want to obtain (given $3 \mathrm{~d}$ with or without colour, predefined quality), the availability of tools and the operating conditions.

According to the chosen method, an operating method has been established which will be described precisely in paragraph 3.2.

\subsection{The maquette}

The second topic is related to the reconstruction of Cultural Heritage and, in particular, we tried to identify the most effective and immediate way for a $3 \mathrm{D}$ representation of the asset.

In an historical age in which digital technologies make it possible to detect an architecture through three-dimensional scanners and photogrammetry and to restore its virtual image, both visually and geometrically corresponding to the original but "navigable" and adjustable on any screen, it is legitimate to ask oneself what is the intrinsic value and the scientific contribution that a physical model (otherwise defined as a maquette) represents.

It is worth, then, to rely on the words of Claude Lévi-Strauss who in his "The Savage Mind" affirms: "What virtue therefore possesses reduction, both in the case of format and in that of properties? It would seem to result from a sort of reversal of the process of knowledge: to know the real object in its totality, we always tend to operate starting from its parts. (...) The scalar reduction reverses this situation: reduced, the totality of the object appears less fearsome; for the fact of being quantitatively reduced, it seems to us qualitatively simplified. (...) through this, the thing can be grasped, weighed in the hand, grasped at a glance" (Lévi-Strauss, 1996).

The intrinsic characteristic of the model is, therefore, the physical permanence of three-dimensionality that allows anyone to understand aspects of architecture that are difficult to represent in two dimensions: structure, relationship with the context, proportions and arrangements of the parts but especially the spatial configuration that the architectural object puts in place. "Its charm surpasses any uncertainty of interpretation thanks to the quality that it has always shared with the building: being ultimately the best representation of architecture (Scolari, 1988). In the long tradition of the model, the representation and restitution of religious and funeral architecture had its peak in antiquity; there are many finds from the Middle East and the Greek and Etruscan civilizations that allow you to know the religious architecture of the time and understand how important the physical representation of buildings was.

Nowadays, talking about archaeological models means first of all talking about isomorphic models, that is to say about objects with a structure and shape similar to the original referent but with different functions: the reconstruction, on the basis of existing emergencies and finds resulting from archaeological excavations, carries out a task of historical-archaeological documentation with strong didactic implications; especially if the final destination is a museum (Benjamin, 1991).

Today's technologies allow us to combine the characteristics of the physical model with the possibilities offered by digital, and 3D printing in particular (Arrighi, 2019). The objective is to obtain a three-dimensional physical representation of the reconstructive hypothesis. The traditional model, integrated with objects printed with FDM (fused deposition modelling) technology, allows us to highlight the elements that led to the formulation of the hypothesis itself. The different materials of the hypothesized parts and the finds, found and digitized, allow to read in an immediate way the path of knowledge carried out.

\section{THE FUNERARY AEDICULAE AND ITS RECONSTRUCTIVE HYPOTHESIS}

\subsection{Archaeological description of the study case}

The subject of this study is the digitization and construction of a model of a funeral monument from the Augustan age, which can be traced back to the funerary aediculae type. The starting point is a considerable nucleus of about 70 fragments, including stone blocks, architectural elements, sculptural parts, which came to light in 1971 in Mantua in the courtyard of the Episcopal Seminary. Among these were of particular interest: two acephalous statues of togated male characters, a female statue with tunic and cloak, two male portrait heads as well as two 
elements of architraves with dedicatory inscriptions of the gens Caepia. All the finds, datable to the Augustan age, had been reused in the construction of the late-ancient walls of the Roman city of Mantua and are pertinent to two funerary monuments of the aediculae type, with a dice base, a colonnade and a spire roof. Most of the fragments and sculptures found lead back to one of the two monuments, which was therefore chosen to elaborate a reconstructive model. The remains of the aediculae mausoleums and the known documentation of stelae and epigraphs reused in civil and religious buildings in the city support the hypothesis of the existence of a monumental funerary area, whose exact location is not documented by known archaeological evidence. (Giordani, 2016). The inscriptions engraved on the remains of the architrave show the names of the clients, belonging to the gens of the Caepii, of the Sabatina tribe, the identity of the citizens of Mantua. The presence in Bologna of inscriptions citing people belonging to the Sabatina tribe led to the assumption that around 40-41 BC, some Mantuan families had moved to those areas after their property had been confiscated because of the redistribution of land to Roman veterans. Perhaps some of those who returned to their home town had brought with them the memory of the funerary monuments erected in the cities of Emilia-Romagna. Aediculae funerary monuments are documented in particular in Bononia, Mutina, Parma and Sarsina, where two almost intact mausoleums are preserved. The Virgilian city also underwent the transformations that took place in the urban systems of the Cisalpine centres during the Augustan Age (Tamassia, A.M, 1994). The most obvious of these is the monumentalisation of the funerary areas in the suburbs. Here the new provincial ruling class found space for visibility for self-celebration and the display of their political and economic power through selfrepresentation. The models, as it happened in Rome and in the centre-south of Italy, derived from the Greek-Hellenistic world, taken up by Augustus himself in the construction of his imposing mausoleum, destined for the burials of his own lineage, the gens Iulia. Adherence to these iconic models also expressed a tangible sign of fidelity to the new political course established by Augustus. In Mantua, too, two great monuments were erected that resemble the Templar type: naiskos with a cell and columns, on a high podium, a spire roof decorated with scales and volutes acroteria, draped statues. Among the discoveries in the area of the Seminar, there is also another cell monument of slightly reduced dimensions compared to the two large newsstand monuments. This was to have only two columns on the facade, where a statue of a togated sitting on a curved chair was placed, an attitude that identifies him as a magistrate. The aediculae monuments found in the necropolis of Sarsina, such as those discovered in Aquileia, in the ancient Appia and in Pompeii are to be considered an example of funerary architecture "imported" from the Hellenistic East. The Sarsina examples, to which the Mantuan mausoleums approach, are more recent and were built in the first decades of the first century AD. In the monuments of Sarsina, inspired by the type of Hellenistic mausoleum, it is visible a cell bounded by columns, which stood on a podium, and was topped by a roof with a cusp roof, whose spire ended with a capital. Inside the spaces that interspersed the columns, there were the statues portraying the dead who, through this sign, showed in an impressive way their social status even after their death (Ortalli, 1987).

\subsection{Digitization}

The digitization work involved 70 objects, including fragments, architectural elements and statues, identified by the Museo Archeologico di Mantova as connected to two monuments of the aediculae type of the gens Caepia, but not exclusively.

The objective of the digitization was the construction of a data archive complete with geometric information and images to describe, in an exhaustive way, the findings and, above all, to foster the virtual reconstruction phase of the Sarsen-type monument. In the context of the digitisation of cultural heritage, the methods currently available refer to the two most common technologies: laser scanner and photogrammetry. Specifically, since the objects are small (with the exception of 3 statues and one recomposed column), it was necessary to choose between 3D triangulation scanners and digital photogrammetry (based on Structure from Motion -SFM and Dense Stereo Matching-DSM algorithms). In literature, there are many comparisons between the two systems, but the discriminators in the choice were, essentially, the metric quality attainable in terms of accuracy and the possibility of acquiring not only geometric information but also radiometric information. As far as the first aspect is concerned, it is a fact that the accuracy of the laser scanner has physical limitations due to the instruments, while for photogrammetry, the problem is reflected in the ability to obtain high-resolution images of very small objects and to design a good geometry for image acquisition. It can therefore be said that, also based on the specific requests presented by the Museo Archeologico, both technologies would have guaranteed a correct result (representation in 1:5 scale, with a maximum error of less than $1 \mathrm{~mm}$ ). What made photogrammetry preferable was the possibility of simultaneously acquiring the geometric aspect and the radiometric value of the surface. The objects to be digitized, in fact, besides being characterized by different materials, in some cases presented traces of coloured surface finishes that had to be digitized correctly. It was therefore decided to proceed with the digitalization through digital photogrammetry, by using Agisoft Metashape software.

To obtain consistent results, a well-defined procedure for the acquisition phase was put in place and used for most objects. In particular:

1) setting of the acquisition environment to ensure stable and homogeneous light conditions. Given the need to acquire radiometrically correct images, the fragments were inserted into a lighting tent with the aim of avoiding direct light reflections or shadow areas if it was possible in accordance with the size of the objects. Three led photo studio lights were used, set with the same intensity, to illuminate the object through the curtain and obtain a diffused light. Colour acquisition was verified with the Color-checker Passport system, which allows you to check the colours of the acquired images. After the initial light setting and without changing the lighting conditions, a number of photographs were taken with the colour palette and white balancing. These operations have been done for each object, avoiding changes in the light conditions during the acquisition. All photographs were then captured in the raw proprietary format (.cr2) of the camera used (Canon Eos 5d Mark III);

2) Multi-image acquisition by a turntable. After placing the object inside the tent and in the centre of the turning plate, the position of the camera was decided, and the shots were taken with an angular step of about $15^{\circ}$. The position of the camera was determined from the lens with the fixed focal length used (35 $\mathrm{mm})$. In order not to change the focal length, the focusing operation was done only in the initial phase and then the focal length has not been changed. This made it possible to calculate, at a later stage, a single calibration for all the photographs of the same object.

Since the objects are characterized by complex shapes (projections, holes, undercuts, areas in shadow) the photographic acquisition was made not from a single point of view, but from several positions, by rotating the support plate. Generally, for each object, the image acquisition was made from several points of view in an initial position (called "straight"). This has allowed to completely digitize one half of the object. Subsequently, the 

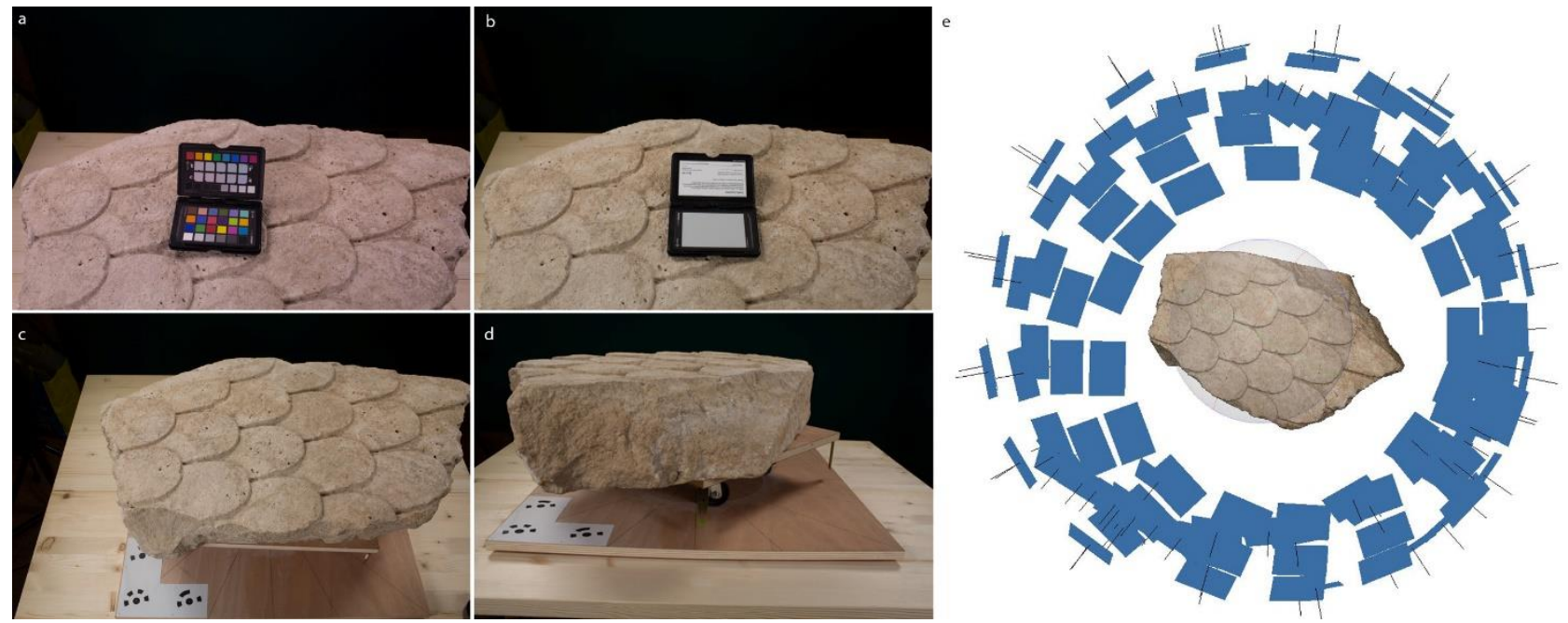

Figure 1: capture a cover fragment. a) image taken with Passport checker for color control b) image with Passport checker for white balancing after color treatment; c) and d) images of the acquisition from different positions.

object was placed upside down (since now called "inverse") and photographs were taken from the same positions. The front band, acquired with the object in both positions, although redundant, has allowed you to orient, during data processing, the two semiblind in a single system;

3) acquisition of reference measurements to scale the photogrammetric model. To scale the point cloud, we chose to use the markers made by Photoscan, in order to take advantage of the self-recognition capability of the software itself. The markers were positioned on the rotating plane and then moved together with the object (as for a single element). They were measured with great precision by a tape (with the graduation of 1 $\mathrm{mm}$ ) in the initial phase and then the data was reused for all processing. To avoid having the same targets with the object in position straight and position inverse, in the second acquisition the targets were covered.

The above procedure was used in almost all objects, except the very large ones that could not be placed inside the tent and the many small ones for which the number of acquisitions was reduced.

In the case of very large objects, the use of the light tent has been omitted and the objects have been positioned on a special rotating support (with greater resistance) and rotated as described above. By not using the curtain, care was taken not to point the light from the headlights directly at the object and to work through more homogeneous reflections. Again, the same colour management system was used (Figure 1).

Only the three statues (already in situ and with a height of about $1.80 \mathrm{~m}$ ) and the column were acquired without placing them on a rotating system but walking with the digital camera around the object.

Shared standard procedures were also used for the data processing phase. After transforming a photograph from the proprietary canon format (.cr2) to .dng format (format required by the proprietary Color-checker Passport software), we calculated a "colour-space" specific for each object that was applied, in the Adobe Lightroom software, to each image and then convert it to .tiff format.

All the images of each object, grouped according to the photographic acquisition position, have been processed in Photoscan.
The first step was to mask the background so that the points necessary for alignment lay only on the object and on the rotating plate.

The next step was the image orientation, cleaning and optimization of the photogrammetric model. The two halves of the object, straight and reverse, have been oriented between them through the function provided by the software ("align chunks") that aligns the clouds with an algorithm similar to ICP (Iterative closest point). In some, however, it was necessary to manually locate the homologous points between the two clouds.

Once the phase of orientation and alignment between point clouds was completed, for each model the dense cloud (with "high mode" set) and the mesh (with "high" parameter) were

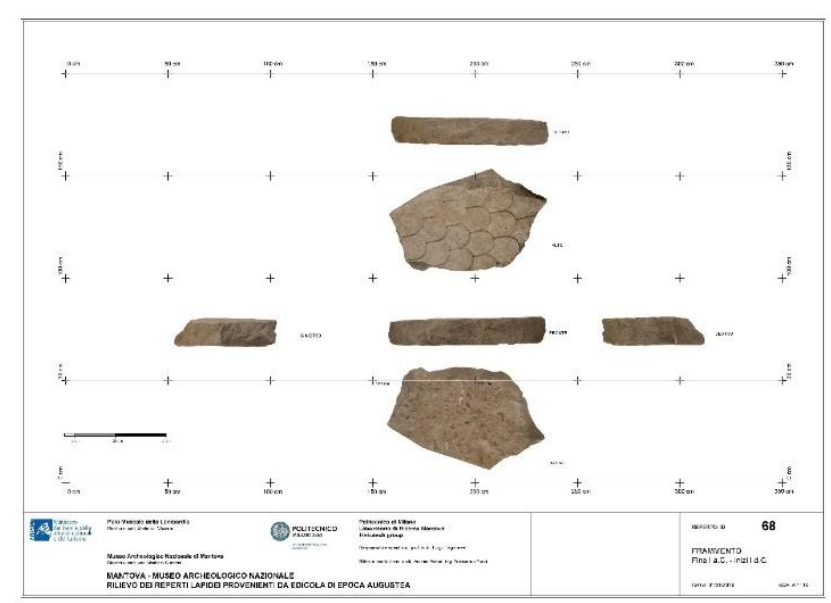

Figure 2: documentation of a single element of the roof. The 6 orthophotos allow to have metric information and to understand the shape and the characteristics of the object.

calculated according to the traditional process provided by the software.

As for the texture, calculated according to the "generic" and "mosaic" settings provided in the software, we chose to use an average pixel size of less than $0.2 \mathrm{~mm}$.

For each model, then, six orthophotos have been extracted, 

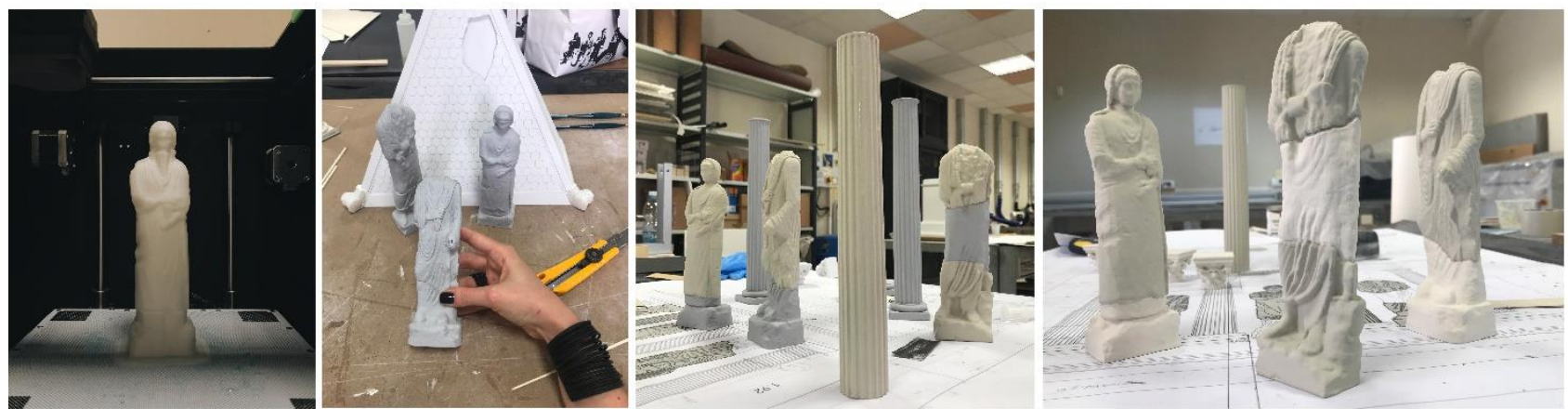

Figure 3: sequence of statues (3D printing, post-production, final finish)

oriented according to the main planes (top, bottom, front, left, back, right) so as to provide a summary sheet for each object, but composed of the 6 views needed to provide the complete description. The orthophotograph was also calculated with a very high GSD of $0.2 \mathrm{~mm}$ in order to also read the material texture (Figure 2). All the orthophotos were inserted in a single sheet with a reference grid to let the user to have all the information at a glance.

\subsection{The model and the museum set-up}

The case of the model of the funerary aediculae monument of the Mantuan family of Caepii is part of the setting up of a new area of the Museo Archeologico Nazionale di Mantova dedicated to monuments and funerary cults. In the museum there are some elements referred to the funerary monument and the main purpose of the model is to suggest a possible three-dimensional reconstruction based on both the exhibits and the knowledge of this type of architecture.

The project for the reconstruction of the funerary monument led to a series of choices tied to the information available and to the deductions on its overall form. Those choices affected the result at different levels: from the architectural reconstruction of the funerary model to the architectural setting.

In particular, since there were no definite data on volume of the monument (the plant could be quadrangular or rectangular, with a closed cell or with one or more openings behind the statues) and since the arbitrary representation of unproven elements was not considered correct, the final physical model, agreed with the Polo Museale Regionale Lombardia and the Soprintendenza Archeologia Belle Arti e Paesaggio di Mantova, Cremona, Lodi, was configured as a section.

All the forehead and about half of its depth are visible entirely while the back coincides with a hypothetical plane of the vertical section that cuts the model and is at the same time a physical element of support, recalculating its profile. The decision to consider the depth equal to its width derives from the similarity of this monument with others (in particular the cusp monuments of the sarsinate type and the monuments of the necropolis of Porta Nocera in Pompei) in which the plant was quadrangular. With regard to the base of the monument, information about the possible subdivision into horizontal bands of stone superimposed rather than the presence of inscriptions or decorative elements are absent, which led to the decision to represent this part as a smooth element lacking in detail.

From a material point of view, the model integrates techniques and materials that are part of the tradition, combining them with the latest technologies applied to this discipline. The main frame of the model is made up of wooden slabs (of different thicknesses) which, each time, make up the different layers and elements of the base podium, the architrave and the cusped roof (figure 4).

The details and the statues were realized through 3D printing of the fused deposition modelling type (figure 3), i.e. an overlapping by layers of HIPS plastic material. The mesh models obtained from the photogrammetric models were scaled, with Geomagic studio, to the correct dimensions of the maquette and then decimated to reach a reasonable and efficient number of faces (as the original number of the real scale was too high). The models were verified to avoid the presence of holes.

Finally, the $3 \mathrm{~d}$ printing instructions for the printer (Zortrax M300) were calculated by the owner software Zsuite, together with the supports necessary to hold up the fused filament.

At the end of the printing process, as usual, a manual intervention was required to eliminate the support and to uniform the surface.

The back of the model, however, was made of opal plexiglas to allow the "closure" of the model from the perceptual point of view, but allowing a certain degree of transparency that suggests an ideal continuation of the architecture.

The contribution of the technologies of digital fabrication (3D scanning) was fundamental in this operation because it allowed to perfectly replicate, and on a small scale, portions of the
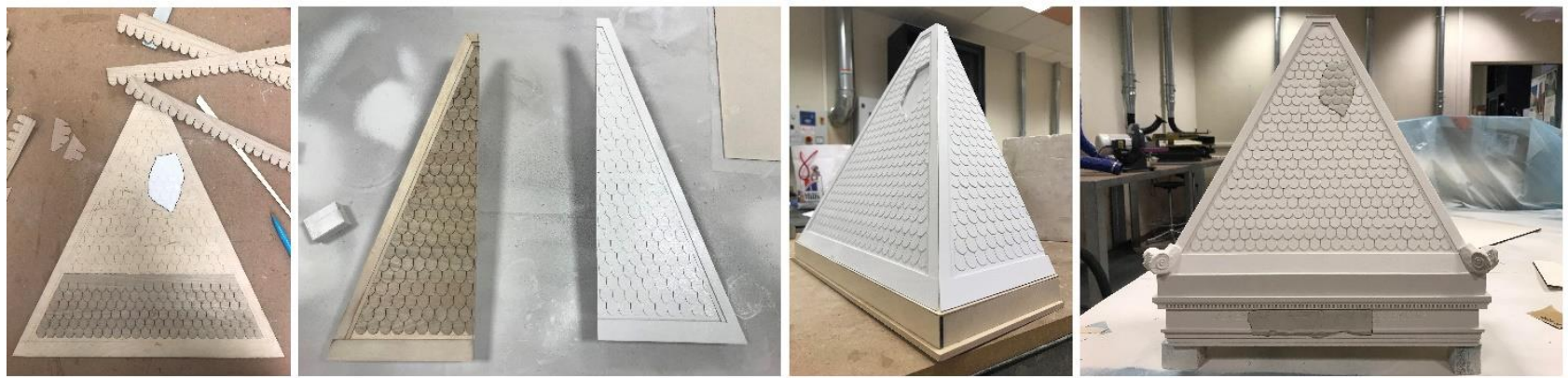

Figure 4: mounting sequence of the cusp cover (scales decoration construction, underpainting, cover assembly and final finish) 

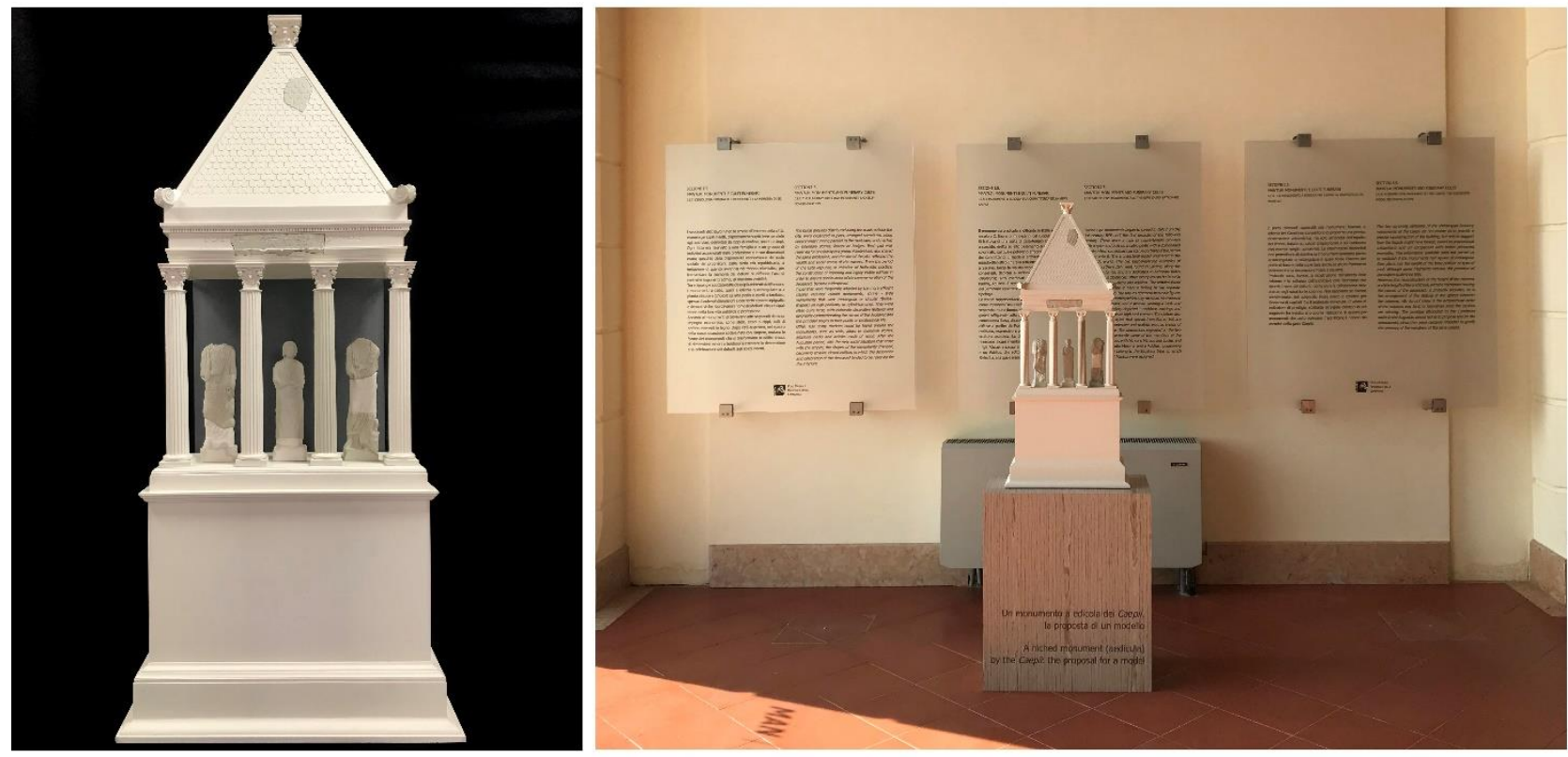

Figure 5: Details of the model and installation at the Museo Archeologico Nazionale di Mantova

monument that, in some cases, had a reference role for the subsequent reconstruction of entire parts of the model. This is the case of the fragment of the roof which provides precise indications about the presence of decoration with scales. The scale reproduction of the model has made it possible to obtain the necessary information (size, shape and thickness) to reproduce the pattern over the entire frontal and lateral surface of the roof, ensuring continuity and formal completeness of the architecture (Figure 3).

The same principle is applicable to the portion of the architrave with the inscription dedicated to the gens Caepia: thanks to this element, it was possible to reconstruct and complete the rest of the architrave in continuity with the existing digitized fragment (Figure 4). In addition to these, the other elements of the model reconstructed by $3 \mathrm{D}$ printing are related to the fragments currently preserved in the museum and to some parts that have required a high degree of detail: the three columns of the Corinthian order, the three statues originally arranged in the spaces that interspersed the columns, the volutes of the roof, the mouldings, the Corinthian capital summit.

In the model, it was chosen to also highlight the process that led to the reconstructive hypothesis. The surface finish of the model, in fact, reveals the paths of its different elements: the lighter parts represent the reconstruction hypotheses, while the darker elements are the original ones, printed in 1:10 scale through the 3D printer (Figure 3-4).

As already mentioned, this model is inserted in a wider context, taking the form of an object that dialogues with the other elements of the exhibition at the Museo Archeologico Nazionale di Mantova. In the physical space of the museum, the findings of the funerary monument were placed in their original position through a careful installation project: the statues and the portions of columns rise on a wooden structure-base on a scale of $1: 1$, positioning themselves at their original height and allowing the visitor, who becomes the measuring element of the space, to understand how imposing this monument dedicated to the memory of a family had to be.

The model, at a scale of 1:10, is placed in the immediate vicinity of the finds allowing an immediate comparison between what exists now and what should have existed in the past. Its size, ten times smaller than reality, allows the visitor to approach and thus satisfy "the need to take possession of the object from as close a distance as possible in the image, or rather in the effigy, in the reproduction" (Figure 5).

In the final analysis, the topicality and importance of the model as a cognitive and research tool are also confirmed by the international architect Mario Botta, for whom "the model of architecture, as proposed, becomes itself an object with its own expressive function. Although strictly faithful to the work it reproduces, the model interprets the geometry and spaces of architecture through cuts and splits and proposes itself as an autonomous sculptural presence capable of suggesting a journey into architecture to the user" (Botta, 2000).

\section{CONCLUSIONS}

The experience described in the article concerns the reconstruction of a funerary monument at the Museo Archeologico Nazionale di Mantova. The interesting aspects concern, first of all, the definition of a precise pipeline for the digitization of archaeological finds, with the aim of optimizing the phases of acquisition, to favour a correct result from the metric and photorealistic point of view. These two features allow the use of digital reproductions in various ways: from studio and database support to tools for designing and communicating a virtual reconstruction.

The experience conducted on the funeral monument also tells the possibility of integrating digital and traditional technologies in favour of a process of communication and dissemination of cultural heritage. The archaeological reconstruction of the monument, although on a scale, starts from a series of hypotheses refined through the comparison with similar cases for historical period, geographical location and function.

However, it is difficult to move from a reconstructive hypothesis to a physical model, given that a physical object fixes the reconstruction in a precise moment, with measures and choices that can no longer be modified. This passage from the reconstruction phase to the physical model was, in the case of the Museo Archeologico di Mantova, validated through the comparison of different finds attributed to the monument itself. 
Following the digitization phase, the finds were used to verify the construction hypotheses: therefore, the columns were used to "scale" the entire monument, the fragment of the frieze dictated the proportions of the architrave and permitted to understand the dedication, while the remains of the roof allowed to build a probable hypothesis of the roof.

\section{ACKNOWLEDGEMENTS}

We thank Polo Museale Regionale Lombardia, directed by Stefano L'Occaso for making the data available and the architects Massimo Ferrari and Claudia Tinazzi who used the data in the new layout project both for the design of the structures and for the layout of the museum. Our thanks also go to the official of the Soprintendenza ai beni archeologici, architettonici e paesaggistici di Mantova, Cremona and Lodi, dott. Maria Grazia Facchinetti.

\section{REFERENCES}

Arrighi, P-A., 2019. 3d printing and 3d scanning for archeology and museums. In: How $3 D$ printing can be used by museums and researchers. archeology-and-useology

Benjamin, W., 1991. L'opera d'arte nell'epoca della sua riproducibilità tecnica. Einaudi, Turin.

Botta, M., 2000. Mario Botta. Modelli di architettura. Alinea, Firenze.

Di Giuseppantonio, P., Di Franco, C., Camporesi, C., Galeazzi, F., Kallmann, M., 2015. 3D Printing and Immersive Visualization for Improved Perception of Ancient Artifacts. In: Presence: Teleoperators \& Virtual Environments 24(3), The MIT press, pp. 243-264.

Galeazzi, F., 2016. Towards the definition of best 3D practices in archaeology: assessing 3D documentation techniques for intrasite data recording. In: Journal of Cultural heritage, 17, Elsevier Masson, pp.159-169.

Gonizzi Barsanti S., Guidi G., 2013. 3D digitization of museum content within the $3 \mathrm{~d}$ icons project. In: ISPRS Annals of the Photogrammetry, Remote Sensing and Spatial Information Sciences, II-5/W1. 10.5194/isprsannals-II-5-W1-151-2013.

Giordani, N., 2016. Mantua: una città romana. Museo Archeologico Nazionale di Mantova, Mantova.

Lévi-Strauss, C., 1996. Il pensiero selvaggio. Il Saggiatore, Milan.

Ortalli, J., 1987. La via dei sepolcri di Sarsina. Aspetti funzionali, formali e sociali. In: Römische Gräberstrassen, Selbstdarstellung-Status-Standard, Munchen, 1985, edited by von Hesberg, H., Zanker, P., Verlag der Bayerischen Akademie der Wissenschaften, Munchen, pp. 156-182.

Renfrew, C., Bahn, P., 2006, Archeologia. Teorie, metodi, pratica. Zanichelli, Bologna.

Scolari, M., 1988. L'idea di modello. In: Eidos, 2, Asolo Arti Editore, Italy, pp.16-38.

Scopigno R., Callieri M., Cignoni P., Corsini M., Dellepiane M., Ponchio F., Ranzuglia G., 2011. 3D models for Cultural Heritage beyond plain visualization. In: IEEE Computer Society, Volume 44, Number 7, pp 48-55.

Tamassia, A.M., 1984. Riflessi della confisca dei terreni. In: Misurare la terra: centuriazione e coloni nel mondo romano. Il caso mantovano. Exhibition catalog, Mantova, febbraio-aprile 1984, edited by Pasquinucci, M., Roffia, E., Tamassia, A.M., Modena, Italy, pp. 89-94. 